\title{
The on-line teaching of robot visual servoing
}

\author{
Carlos Perez-Vidal', Nicolas Garcia', Enric Cervera², Luis Gracia ${ }^{3}$ and Jose Maria Sabater ${ }^{1}$ \\ ${ }^{1}$ Department of Industrial Systems Engineering, Miguel Hernández University, Elche \\ (Alicante), Spain \\ ${ }^{2}$ Department of Computer Science and Engineering, Jaume-I University, Campus Riu Sec, \\ Castelló, Spain \\ ${ }^{3}$ IDF Institute, Technical University of Valencia, Valencia, Spain \\ E-mail: carlos.perez@umh.es
}

\begin{abstract}
Visual servoing uses the visual information provided by cameras to control the movement of a robotic system. This paper presents an international on-line course aimed at BSc, MSc and PhD students in this subject. The course lasted for eight weeks, and its objective was to provide a general vision of those aspects related to the course theme including a special incentive: the professors teaching the course were the most important experts in this field at a global level, signifying that the students were able to gain access to a potentially higher quality of teaching than that available at an individual traditional university.
\end{abstract}

Keywords distance learning; Internet; JaViss; visual servoing

Visual servoing is a technique which uses the visual information provided by artificial vision cameras to control a robot's movements. This control technique increases the flexibility of robotic systems and is among those currently undergoing a boom.

Continuing education is, on the other hand, more than simply complementary education, but is a necessity for those professionals or academics who wish to remain up-to-date in several disciplines such as engineering. This paper therefore presents an on-line training system for the teaching of visual servoing in engineering, which allows its students to connect to the course website and complete training units to which they have controlled access, i.e., they initially have access to only one unit until it has been successfully completed, at which point they are able to access the subsequent one. A further feature of additional note is the existence of a 'forum of experts', made up of the course teachers.

Each teaching unit was divided into three parts:

- The unit's basic contents, in which the students had access to one or more theory subjects in pdf format which they had to read and understand;

- Widening of their knowledge through participation in a forum and through modifications of the code and algorithms seen in the teaching unit. After completing the study stage in each thematic unit (and before being able to move on to the next unit) it was necessary to successfully complete the final part;

- Evaluation of acquired knowledge through a test. The teacher(s) of the course's didactic unit set pieces of work and/or exercises that the students had to complete and send to the teacher, who evaluated them and made a note of the progress made in each subject.

International Journal of Electrical Engineering Education $48 / 2$ 
Once each training unit had been successfully evaluated, the students were able to pass to the next unit, such that once all the units in the visual servoing course had been completed they would receive a course progress certificate.

One of the pedagogic objectives of this on-line course was that the students would understand the great potential of forums, in which criticising the information found may be of great help in both this and other subjects. The course page therefore had an associated forum to allow the students to compare their ideas and results both with their fellow students and with the course's teaching staff. The teachers on this on-line course were one of its greatest differentiating characteristics since they were experts of the highest prestige at a global level in the visual servoing area.

Finally, this paper presents a study of the repercussions that the course had upon the work that the students carried out. This shows that some of the students have had a large amount of work published since their participation on this course. We conclude with a description of the interaction between the students and their teachers, which has been one of the course's major achievements.

\section{Background and motivation}

New developments in computers and multimedia creation programmes have allowed many teachers to digitise teaching material. Both the capacity for content creation and its technical quality and finish have increased, with resulting positive repercussions on the quantity and quality of students' access to information, particularly in distance learning. This may either replace or be complementary to traditional methods. Process simulators or computer simulated practices thus allow students to study without being tied to a rigid timetable and physical location.

The cost of equipment and security are some of the most important restrictions in the teaching of robotics. Consequently, recent years have seen a huge emergence of tele-robotics and virtual laboratories with which to support a great variety of control theory, robot programming, tele-operation and trajectory planning disciplines. ${ }^{1-4}$ Visual servoing techniques use the information provided by one or several cameras to control a robot's movement. Although the first systems of this type date back to the end of the 1970s and beginning of the 1980s, a true increase in publications dealing with this theme did not take place until the middle of the 1990s, and was owing to the availability of computational power of vision systems. Existing technology currently allows the realisation of low-cost visual servoing tasks, and its bibliography is now so extensive that it is even available in book shops (such as ViSP 10, which allow the implementation of visual control schemas). Therefore, one of the fundamental objectives of the course was to provide the students with an electronic bibliography both at a theoretical and a practical level.

In order to achieve the fixed objectives with an on-line Internet course the students worked with a visual servoing Simulator which they were able to download from the course website and install, test and modify. The use of crossed platforms and network-aware technology was decisive in the good working of the application. A basic knowledge of computing and structured programming allowed the students to 
implement new visual servoing algorithms and to carry out tests with them. The course's theoretical and practical material was prepared by the most highly recognized researchers in Europe, Japan, the United States and Australia. All teaching took place via the Internet using the Moodle course management system and a total of 20 students from Europe, America and Asia participated on it.

However, one of the problems with these advanced learning techniques is the evaluation of knowledge acquired by students. The aptitude tests that have to be carried out require the student's physical presence. In our case this problem was sometimes solved by the teachers carrying out personalised tests for each student, thus avoiding the student's presence in a final test.

\section{Objectives}

The creation of a system of this nature necessitates the same amount of time and dedication regardless of the number of people by whom it will be used, so the effort made is justified by the amount of potential students who may be interested in participating on the course and who may do so again in the future.

The Internet is currently one of the most useful tools for teaching but, as occurs with any tool, an in-depth knowledge of it is necessary if full advantage is to be taken of its potential. During the realisation of this course through the Internet, a guided tutorial took place to allow the students to learn the specific philosophy necessary to surf the 'Net' and to discover particular classic websites containing both theoretical and practical information concerning visual servoing. Table 1 shows how the teaching on this course was structured into thematic units. The programme also considered a structure of exercises, shown in Table 2.

\section{Moodle for robotics}

Moodle is a course management system (CMS). It is free software with open code packages, designed according to pedagogic principles to allow teachers to create on-line courses.

Figure 1 shows the course's navigation window. It is important to emphasise that all the material created to access the Web was obtained without writing a single line of HTML code. Moodle provides all the models which are necessary to create and hang the Web pages and multimedia files, along with the forums, chats, etc. The 'course planner' organises the tasks during the realisation itself, and gradually presents information to the students as the weeks go by and they successfully complete the contents.

Table 3 lists the teachers who participated. They are the eight recognised experts in visual servoing at a global level:

The course teachers all found the user interface extremely useful, and despite having no prior experience of using Moodle, none needed special instructions to teach the course with it. 20 students, mainly European, with some Asian and Latin American students, enrolled on the course. Almost none of them had had any previous experience in using Moodle, but all quickly adapted to it.

International Journal of Electrical Engineering Education $48 / 2$ 
TABLE 1 Organisation of taught subjects into thematic units

\begin{tabular}{|c|c|}
\hline \multirow{8}{*}{$\begin{array}{l}\text { Subject } 1 \text { (W1): Introduction to } \\
\text { visual servoing }\end{array}$} & 1.1. Introduction \\
\hline & 1.2. Visual servoing schemas \\
\hline & 1.3. Homogenous transformations \\
\hline & 1.4. Movement of rigid solids \\
\hline & 1.5. The fundamentals of computer vision \\
\hline & 1.6. Robot cinematics and dynamics \\
\hline & 1.7. Sensor-based control: task function summary \\
\hline & 1.8. Applications of visual servoing systems \\
\hline \multirow{5}{*}{$\begin{array}{l}\text { Subject } 2 \text { (W2): Visual servoing } \\
\text { modelling }\end{array}$} & 2.1. $2 \mathrm{D}$ visual characteristics \\
\hline & 2.2. Trajectory planning in the image \\
\hline & 2.3. 3D characteristics \\
\hline & 2.4. Omni-directional vision \\
\hline & 2.5. Linked vision and structured light \\
\hline \multirow{2}{*}{$\begin{array}{l}\text { Subject } 3 \text { (W3): Classical } \\
\text { approximations }\end{array}$} & 3.1. Image-based visual servoing \\
\hline & 3.2. Position-based visual servoing \\
\hline \multirow{4}{*}{$\begin{array}{l}\text { Subject } 4 \text { (W4 \&W5): Hybrid } \\
\quad \text { approximations }\end{array}$} & 4.1. $\quad 2 \frac{1}{2} \mathrm{D}$ \\
\hline & 4.2. $2 \mathrm{D}$ visual servoing approximations \\
\hline & 4.3. Switching approximations \\
\hline & 4.4. E2D visual servoing \\
\hline \multicolumn{2}{|c|}{ Subject 5 (W6 \&W7): Advanced approximations of image based visual servoing } \\
\hline & 5.1. Intrinsic-free visual servoing \\
\hline & 5.2. Visual servoing using Second order efficient minimisatior \\
\hline & 5.3. Task sequencing for visual servoing \\
\hline \multicolumn{2}{|l|}{ Subject 6 (W8 \& W 9): Robustness } \\
\hline & 7.1. Introduction to the robustness of visual servoing systems \\
\hline & 7.2. Visibility restrictions \\
\hline & 7.3. Image Outliers \\
\hline & 7.3. Integration of real characteristics for visual servoing \\
\hline
\end{tabular}

TABLE 2 Set exercises with completion dates

\begin{tabular}{llll}
\hline W1 & Introduction to visual servoing & (Ex.1: exercises and test) & \\
W2 & Visual servoing modeling & (Ex.2: exercises and test) & (DEADLINE Ex.1: 27/10) \\
W3 & Classical approximations & (Ex.3: practical exercises) & (DEADLINE Ex.2: 4/11) \\
W4 & Hybrid approximations (I) & (Ex.4: Practical exercises) & (DEADLINE Ex.3: 11/11) \\
W5 & $\begin{array}{l}\text { Hybrid approximations (II) } \\
\text { Advanced approximations of } \\
\text { W6 }\end{array}$ & (Ex.5: practical exercises) & \\
& $\begin{array}{c}\text { image-based control (I) } \\
\text { Wdvanced approximations of } \\
\text { image-based control (II) }\end{array}$ & & (DEADLINE Ex.5: 2/12) \\
W8 & $\begin{array}{c}\text { Robustness (I) } \\
\text { Robustness (II) \& Applications }\end{array}$ & (Ex. 6: practical exercises) & \\
W9 & & & (DEADLINE Ex.6: 16/12) \\
\hline
\end{tabular}

The course material consisted of presentation files of the subjects and of references to relevant papers, (thus promoting Internet searching). Material could be downloaded in pdf from the course website (promoting the use of additional material). Some of the presentations had additional audio content, which was very well 


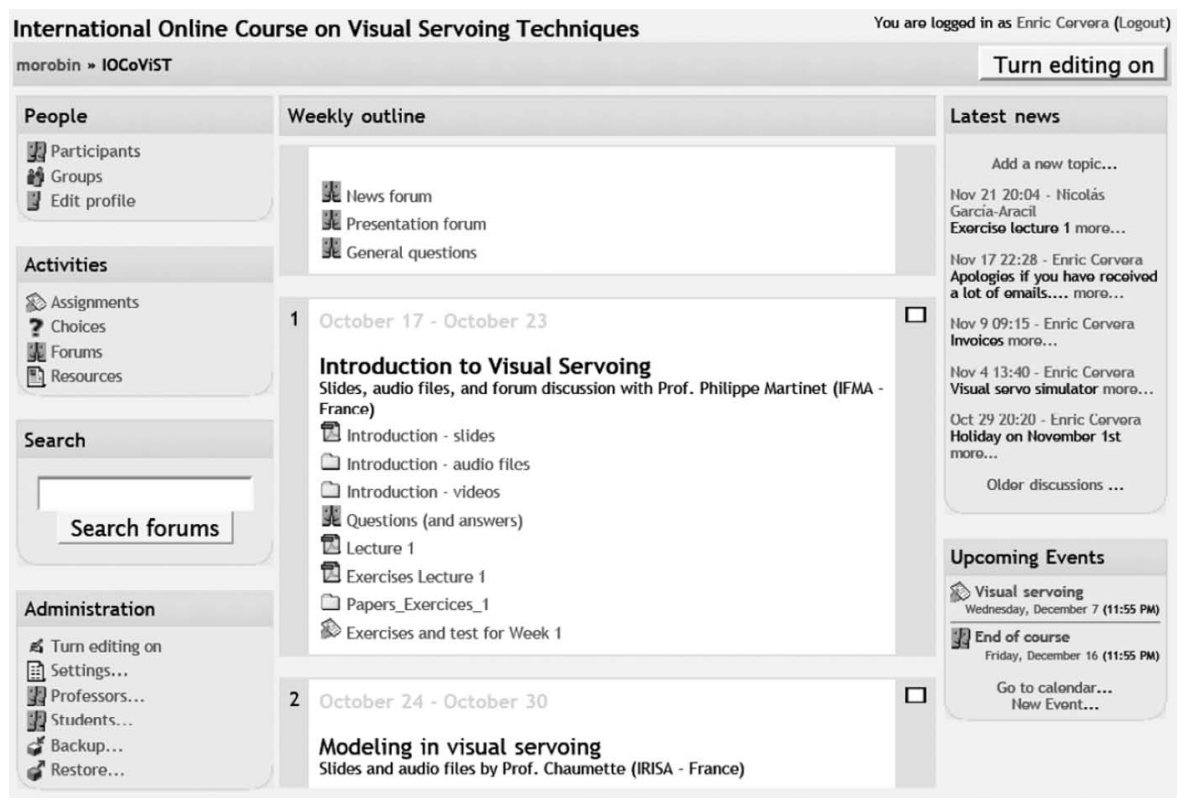

Fig. 1 Moodle interface of visual servoing on-line course.

TABLE 3 Participating teachers and affiliations

Peter Corke

François Chaumette

Ezio Malis

Philippe Martinet

Danica Kragic

Koichi Hashimoto

Greg Hager

Seth Hutchinson
CSIRO, Australia

IRISA, France

INRIA, France

Blaise Pascal University, France

KTH, Sweden

Tohoku University, Japan

JHU, USA

UIUC, USA

received by the students. At the end of each subject the students had to complete exercises and tests and then send their answers directly to the course website. The teachers provided feedback electronically via the website.

This also created discussions and interaction in the course forum, which gave the students direct access to the teachers, thus generating feedback from the expert who had taught the subject. Although the conversations (in the forum) were, on occasions, rather slow as a result of the time difference in various countries (both for the teachers and for the students), this did not pose a considerable problem as regards satisfaction with its use.

The system monitored each of the users' activities, thus allowing it to detect problems in the functioning of tools and enabling tracking of the students' continu- 


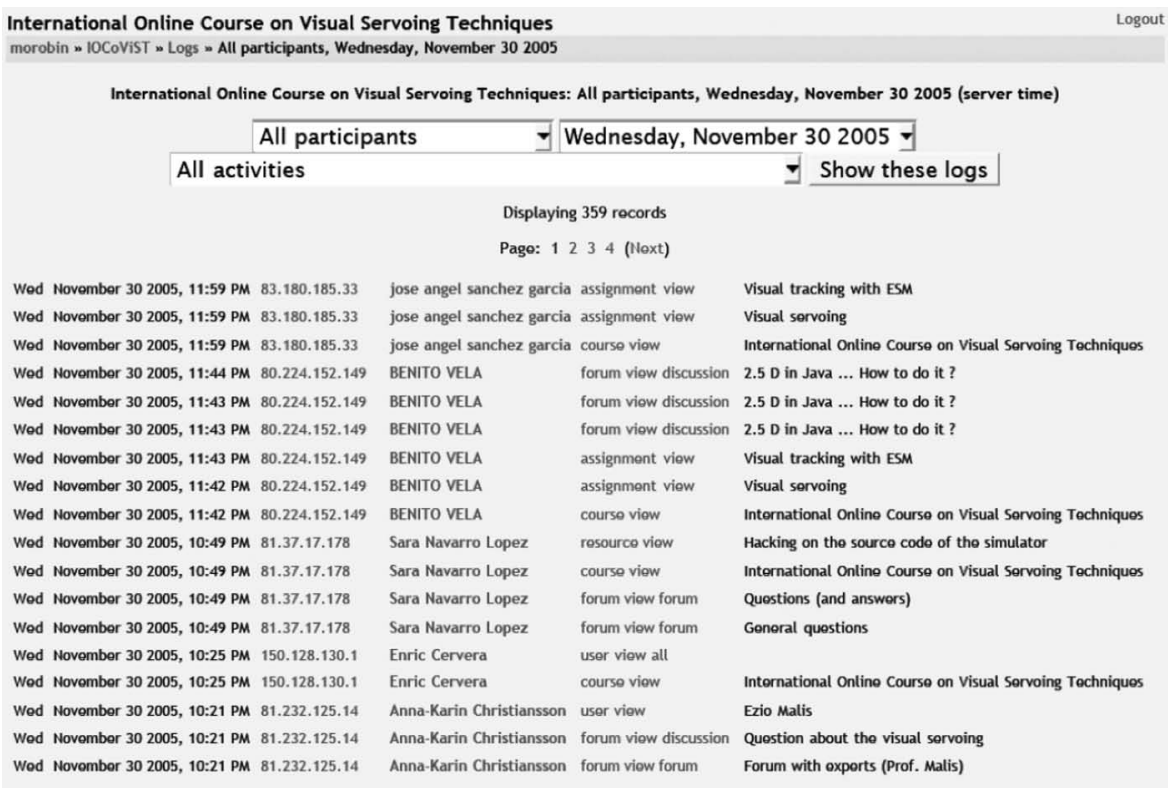

Fig. 2 Database of accesses made to Server.

ation on the course. As Fig. 2 shows, it was possible to monitor the number of accesses and the time taken by each user, his/her IP address and the contents accessed. Thus it was possible to find out in some detail the situation of a student not connecting to the course over several weeks. In this case the organisers sent e-mails to the student and were able to discover whether this was owing to the restrictions of their work or was caused by specific problems with their Internet connection.

\section{Multi-platform simulation software}

The first requirement for the software on a distance course is that it must be compatible with any platform (Windows, Unix/Linux, MAC). The use of multi-platform development kits, which are easy to download and install, is necessary in such cases. In the past, we have worked with MATLAB toolboxes, ${ }^{9}$ but there are other software packages for robotics such as ViSP, ${ }^{10}$ which is very powerful but is only available for certain platforms. We eventually chose JaViSS, ${ }^{11}$ an object-oriented multi-platform simulation software. Visual servoing tasks can be defined in a flexible and extendable manner for cameras anchored to Cartesian movements or to serial link manipulators (industrial robot arms), thus providing 3D visualisation in real time from the control camera or from external auxiliary cameras. Another of the software packages used for the tracking modules were the ESM bookshops. ${ }^{13}$ 


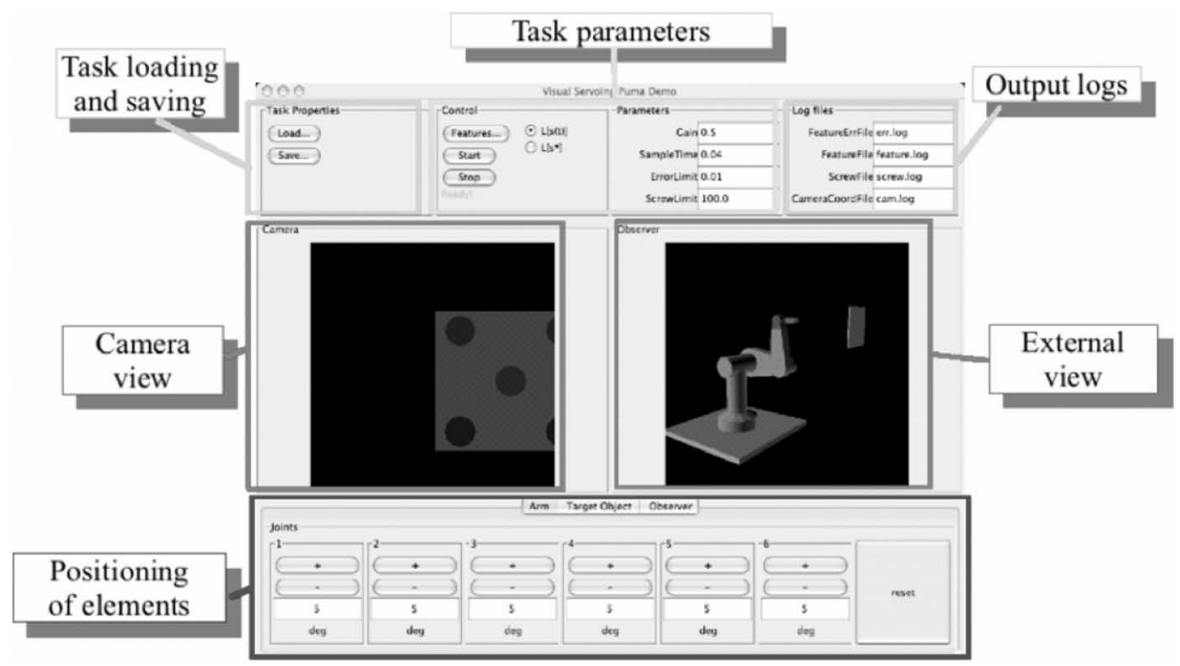

Fig. 3 Graphic user interface of visual servoing simulator.

The main window of the simulator and the user interface are shown in Fig. 3 and consist of:

- A task properties panel to upload and save the parameters (characteristics, initial and desired position, control parameters).

- A task parameter panel, which selects the features option and certain task parameters (gain, sampling time, error threshold), along with the interaction matrix (in the equilibrium or in the current interation). This includes two buttons to begin and end the simulation.

- An output log panel, in which the user defines the names of the files in which the output files will be stored.

- Camera views. In the frontal panel presented, the left-hand view shows the image of the camera which is mounted on the robot's end effecter, while the right-hand image is obtained from an external camera.

- Element control panel, which allows any object in the scene to be moved: the user configuration to move the arm (articular movement), the characteristic object or the external observation cameras (Cartesian movement).

The students were encouraged not only to carry out simulations by analysing their results, but to also to create new control algorithms and test them. To do this, they were able to download the source code, modify, compile and execute it. The simulator is entirely programmed in Java, ${ }^{14}$ which is both a programming language and a platform. As its designers state, it is a high-level language with neutral architecture, and is object oriented, portable, distributed, high loan, multithread, robust, dynamic and secure.

In Java, the source code files are not compiled in the processor's native language. Instead, it generates bytecodes, the machine code of Java Virtual Machine. The

International Journal of Electrical Engineering Education 48/2 

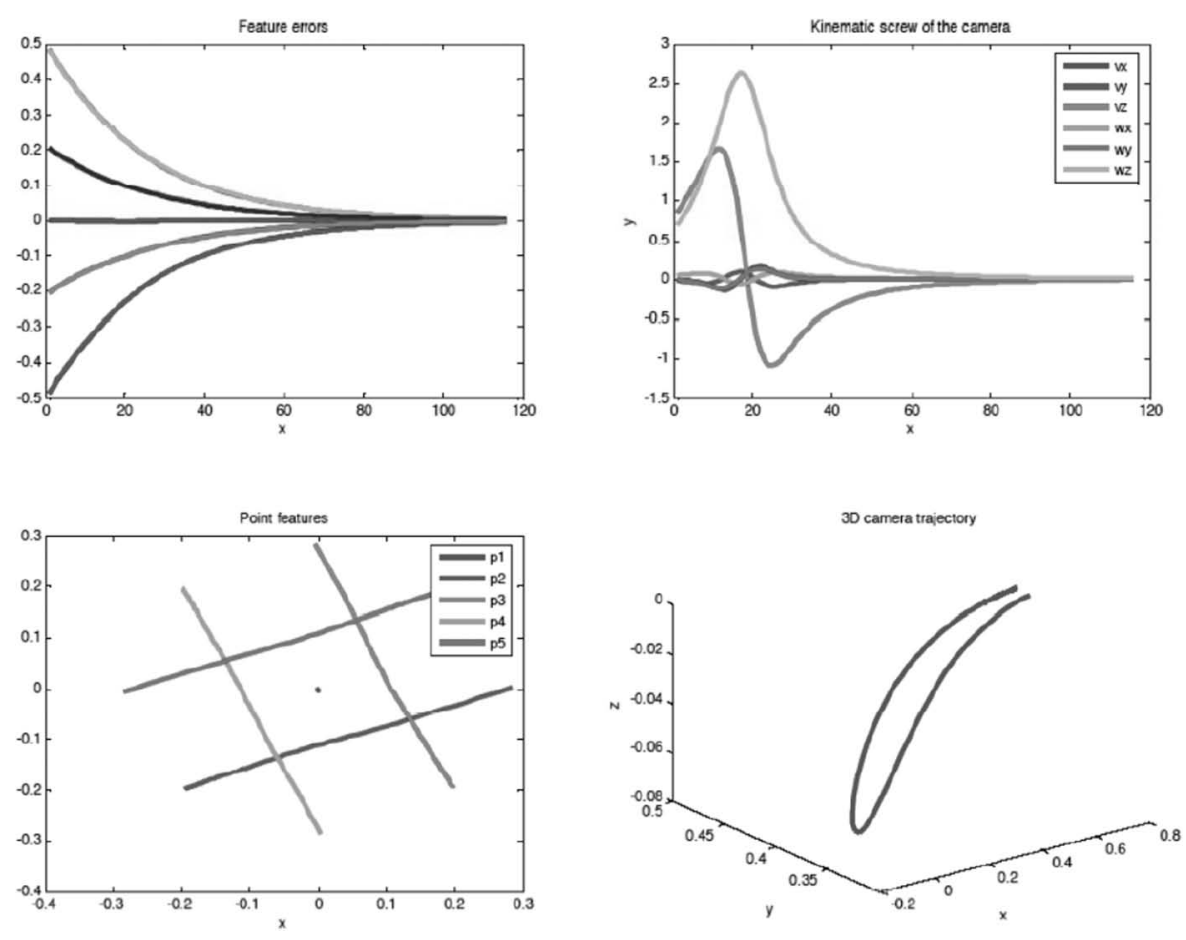

Fig. 4 Graphs of a typical visual servoing task simulation.

Java Launcher Tool executes the application with an instance to Java Virtual Machine. Since Java Virtual Machine is available for several operative systems, the same compiled code is capable of working in Microsoft Windows, Linux or MacOS.

Teachers and students were able to install JaViSS in both Windows and in Linux without any difficulties. JaViSS does not have plotting commands to show the results of the simulations. All the information generated is stored in a file in ASCII format. Data can be converted into graphs by using any Standard programme such as MATLAB or gnuplot, as is shown in Fig. 4 (the course website provided examples to plot each data registration by using the gnuplot tool).

\section{Course forum}

The course forum was divided into two parts, of which one was private and could only be accessed by the course students, and the other was public and could be accessed by any internaut who was not enrolled.

Participation in the forum was distributed in such a way that a set of experts participated in each of the units (Table 4). 
TABLE 4 Participation of experts in the forum

\begin{tabular}{ll}
\hline W1 & Prof. P. Martinet (IFMA-France) \\
W2 & Prof. D. Kragic (KTH-Sweden) \\
W3 & Dr E. Cervera (UJI-Spain) \& Dr N. Garcia (UMH-Spain) \\
W4 & Prof. G. Hager (JHU-USA) \& Prof. K. Hashimoto (IC-Japan) \\
W5 & Prof. S. Hutchinson (UIUC-USA) \& Prof. P. Corke (CSIRO-Australia) \\
W6 & Prof. E. Malis (INRIA-France) \\
W7 & Prof. F. Chaumette (IRISA-France) \\
W8 & Dr E. Cervera (UJI-Spain) \& Dr N. Garcia (UMH-Spain) \\
W9 & Dr E. Cervera(UJI-Spain) \& Dr N. Garcia (UMH-Spain) \\
\hline
\end{tabular}

\section{Publications}

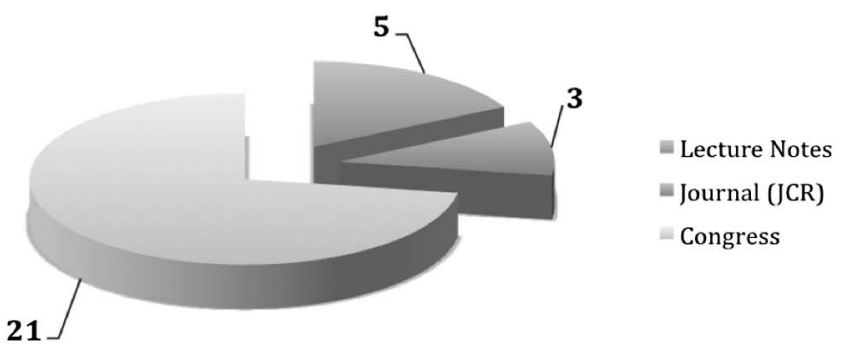

Fig. 5 Type of publications.

\section{Repercussions of the course for participating students}

20 students were enrolled on the course, all of whom participated actively. After participating on the course, four people have defended their doctoral theses ${ }^{23,20,35,39}$ on the theme, one person has presented his MSc in Spain ${ }^{29}$, and several papers have been published in international congresses and journals.

Of the 20 course participants, 55\% (11 of them) have had some sort of work relating to the course theme published after its completion, $36 \%$ of these being 1 first-time publications on visual servoing. 21 participants have published in international congresses or conferences (related to visual servoing) after completing the course: ${ }^{15-18,21,22,40-55} 5$ have been published in Lecture Notes: $:^{31,32,34,36,37}$ and 3 in indexed journals: ${ }^{19,30,33}$ (see Fig. 5). Some of the course participants have published a large amount of research work a year after completing the course. ${ }^{41-45}$

Another relevant issue which should be highlighted is the close contact that has been established between teachers and students; $30 \%$ of students claim to have maintained some type of contact with the course teachers. Indeed, two of them (student $\mathrm{X}$ and student $\mathrm{Y}$ ) have published relevant papers together with some of the professors (Kragic, Hutchinson and Cervera).

International Journal of Electrical Engineering Education 48/2 


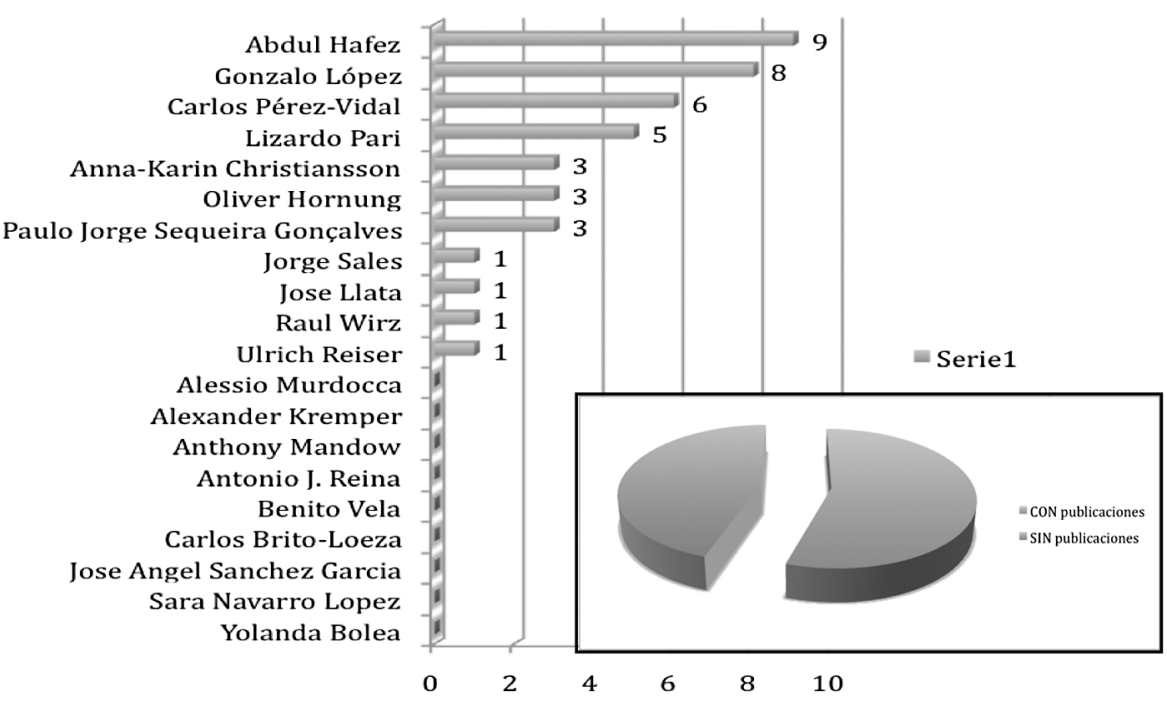

Fig. 6 Graph of publications by students after the course.

\section{\% TEACHING ACTIVITY}

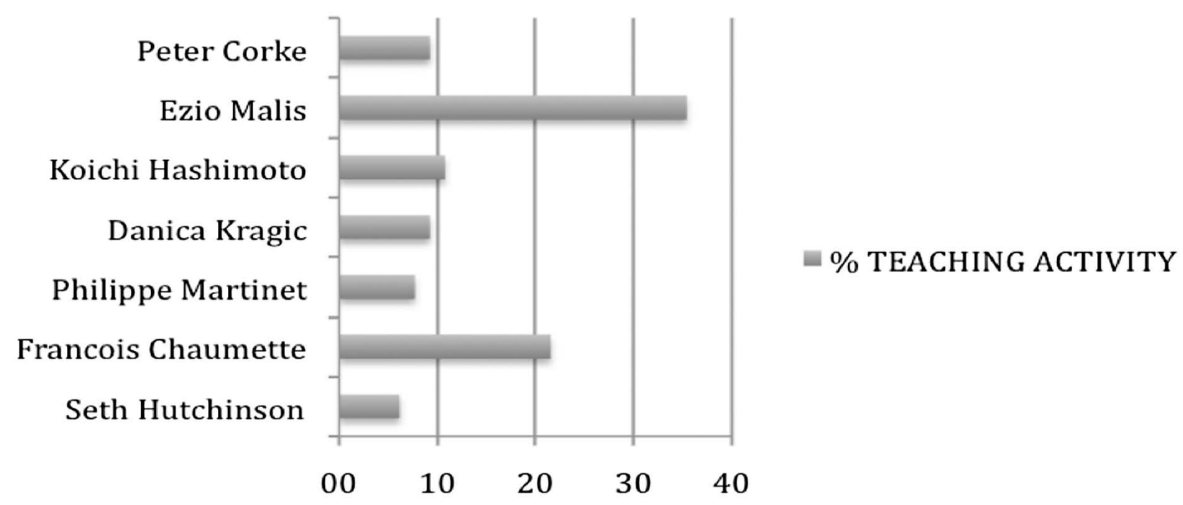

Fig. 7 Activity graph of teachers measured as number of participations (forum, documentation, etc.).

Figure 6 shows the number of publications per student after completing the course. The average number of publications for all students is 2.05 , and the average number of publications between students with some publication is 3.72 .

An analysis of the teachers' and students' activities during the course may provide us with an idea of the dedication to and advantage taken of the course respectively. The teacher's participation consisted of an average of approximately $8 \%$ (Fig. 7). We should, however, highlight an important aspect of the grading. The participation 


\section{\% ACTIVITY}

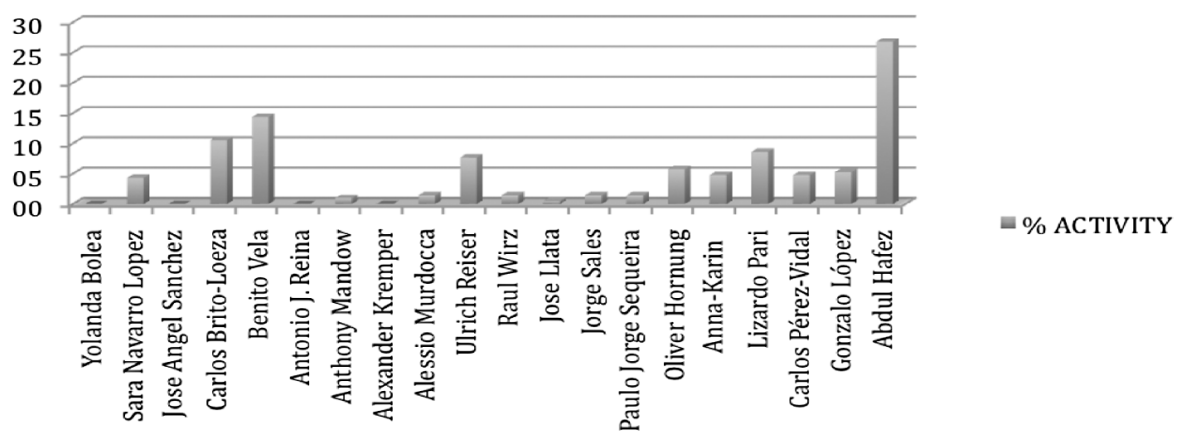

Fig. 8 Activity graph of students measured as number of participations (forum, documentation, etc.).

of all of the teachers was exceptional, but since we are dealing with data in percentages, and owing to the extremely high level of participation by two members, the ratio of the others is lower, signifying that we should not lose sight of the dedication of all of them.

As regards the students, their participation in \% coincides with the publications obtained after their papers had been written (compare the data in Fig. 8 to those in Fig. 6). The student with the greatest number of website visits also had the greatest number of publications of the participants, although it is also true that other students participated very actively on the course and have not had their research on this theme published.

\section{Conclusions}

As this course has shown, distance learning can break down physical and temporal limitations to study, and improve some educative systems which are currently defective. The extension of tutored teaching of a distance nature allows better results to be obtained and a better yield of distance hours that students can dedicate to a subject or theme. It also constitutes an important tool for continuous education, giving current postgraduate distance learning courses an important experimental set up.

Furthermore, the speed of present-day Internet connections offers the possibility of quality distance teaching with a large quantity of material, which has hitherto not been possible. This also opens up a whole new range of possibilities for developing countries or regions which would have limited access to teaching material which is usually expensive. In addition, even in developing countries, the study possibilities for disabled people increase enormously thanks to facilities which imply that they can be educated in their own homes.

This paper describes a satisfactory experience of running an on-line robot visual servoing course, along with the resources that were necessary to plan and manage

International Journal of Electrical Engineering Education 48/2 
the educational activities. Moreover, both the teachers and the students rate the learning experience as being highly satisfactory. The current advances in telerobotics and tele-laboratories could make it possible to run a course using real robots and yet maintaining security guarantees in the future. Multi-platform or cross-platform languages allow a large number of students to use the applications developed, which can easily be placed on the Internet. The modifications to the course were made thanks to the contributions of the students and teachers, who indirectly carried out a large testing task of the applications involved. We have also worked to make the simulator as realistic as possible by incorporating the manipulators' dynamics. With regard to the repercussions of the course, although we are unable to quantify them numerically, the course organisers were satisfied with the success attained after analysing the data shown in Section 7, and we have received comments from the teachers and students, both while the course was taking place and at present whilst writing this report (3 years later).

\section{Acknowledgements}

The authors would like to thank Peter Corke for allowing us to use part of his code from the Robotics Toolbox. We should also like to express our gratitude to the Ministry of Education for their support, and in particular to François Chaumette and Ezio Malis, without underrating the invaluable help of Philippe Martinet, Danica Kragic, Koichi Hashimoto, Greg Hager, Seth Hutchinson, and Peter Corke himself for their collaboration as teachers on this course.

\section{References}

1 R. Marín, P. J. Sanz and A. P. del Pobil, 'The UJI Online Robot: An education and training experience', Autonomous Robots, Special Issue on Internet and OnLine Robots, 15(3) (2003), 283-297.

2 C. Cosma, M. Confrente, D. Botturi and P. Fiorini, 'Laboratory tools for robotics and automation education', in Proc. 2003 IEEE Int. Conf. on Robotics \& Automation, Taipei, Taiwan, September 2003 (IEEE, Piscataway, NJ, 2003), pp. 3303-3308.

3 D. Fabri, C. Falsetti, S. Ramazzotti, and T. Leo, 'Robot control designer education on the web', in Proc. 2004 IEEE Int. Conf. on Robotics \& Automation, New Orleans, LA, April 2004 (IEEE, Piscataway, NJ, 2004), pp. 1364-1369.

4 K. S. Rawat, and G. H. Massiha, 'A hands-on laboratory based approach to undergraduate robotics education' in Proc. 2004 IEEE Int. Conf. on Robotics \& Automation, New Orleans, LA, April 2004, (IEEE, Piscataway, NJ, 2004), pp. 1370-1374.

5 E. Cervera and P. Martinet, 'EURON Summer School on Visual Servoing', http://www.robot.uji.es/ EURON/visualservoing/summerschool/, Benicàssim, Spain, September 2002.

6 E. Cervera, P. Martinet, F. Chaumette, E. Malis and K. Hashimoto, 'IEEE/RSJ IROS Tutorial on Advanced Visual Servoing', http://www.robot.uji.es/EURON/visualservoing/tutorial/, Sendai, Japan, September 2004.

7 E. Cervera and N. M. García-Aracil, 'International Online Course on Visual Servoing', http://www. robot.uji.es/IOCoViST/, 2005.

8 'Moodle: A Free, Open Source Course Management System for Online Learning', http://www. moodle.org.

9 E. Cervera, 'Visual Servoing Toolbox for Matlab/Simulink', http://vstoolbox.sourceforge.net, 2003. 
10 E. Marchand, F. Spindler and F. Chaumette, 'ViSP for visual servoing', IEEE Robotics \& Automation Magazine, Special Issue on Software Packages for Vision-Based Control of Motion, 12(4) (2005), 40-52.

11 E. Cervera, 'JaViSS - Java-based Visual Servo Simulator'.

12 http://www.robot.uji.es/research/projects/javiss

13 S. Benhimane and E. Malis, 'Real-time image-based tracking of planes using efficient second order minimization', in Proc. IEEE/RSJ Int. Conf. on Intelligent Robots Systems, Sendai, Japan, October 2004 (IEEE, Piscataway, NJ, 2004), pp. 943-948.

14 Java Technology, http://java.sun.com

15 G. López-Nicolás, C. Saguiés, J. J. Guerrero, D. Kragic and P. Jensfelt, 'Nonholonomic epipolar visual servoing', in IEEE International Conference on Robotics and Automation, May 2006, (IEEE, Piscataway, NJ, 2006), pp. 2378-2384.

16 G. López-Nicolás, S. Bhattacharya, J. J. Guerrero, C. Sagüés, and S. Hutchinson, 'Switched homography based visual control of differential drive vehicles with field-of-view constraints', in Proc. IEEE International Conference on Robotics and Automation, April 2007 (IEEE, Piscataway, NJ, 2007), pp. $4238-4244$.

17 G. López-Nicolás, C. Sagüés and J. J. Guerrero, 'Shortest path homography-based visual control for differential drive robots', in Goro Obinata and Ashish Dutta (Eds), Vision Systems (I-Tech Education and Publishing, Vienna, Austria, 2007), pp. 583-596.

18 G. López-Nicolás, C. Sagüés and J. J. Guerrero, 'Homography-based visual control of nonholonomic vehicles', in Proc. IEEE International Conference on Robotics and Automation, April 2007 (IEEE, Piscataway, NJ, 2007), pp. 1703-1708.

19 G. López-Nicolás, C. Sagüés, J. J. Guerrero, D. Kragic and P. Jensfelt, 'Switching visual control based on epipoles for mobile robots', Robotics and Autonomous Systems, 56(7) (2008), 592-603.

20 G. López-Nicolás, 'Visual Control of Mobile Robots Through Multiple View Geometry', PhD Thesis, University of Zaragoza, Spain, June 2008.

21 G. López-Nicolás, C. Sagüés and J. J. Guerrero, 'Parking with the essential matrix without short baseline degenerecies', in Proc. IEEE International Conference on Robotics and Automation, May 2009 (IEEE, Piscataway, NJ, 2009),

22 G. López-Nicolás, M. Sfakiotakis, D. P. Tsakiris, A. A. Argyros, C. Sagüés and J. J. Guerrero, 'Visual homing for undulatory robotic locomotion', in Proc. IEEE International Conference on Robotics and Automation, May 2009 (IEEE, Piscataway, NJ, 2009).

23 C. Pérez, 'Control of Robots Manipulated using Visual Information: Application to the Estimation of Movement of Objects', PhD Thesis, Department of Industrial Systems Engineering, Universidad Miguel Hernández, Spain, 2008.

24 C. Pérez, O. Reinoso, N. García, J.M. Sabater, J.M. Azorín and L. Gracia, 'Improvement of the visual servoing task with a new trajectory predictor. The Fuzzy Kalman Filter', in Proc. International Conference on Informatics in Control, Automation and Robotics (ICINCO 2007), Angers, France, 9-12 May, 2007.

25 C. Pérez, N. García, O. Reinoso, J. M. Sabater and J. M. Azorín, 'Object trajectory prediction. Application to Visual Servoing', in Proc. European Control Conference ECC'07, Kos, Greece, 2-5 July 2007.

26 C. Pérez, R. Morales, N. García, J.M. Azorín, J.M. Sabater and E. Cervera, 'Autonomous surgical robot using visual servoing in the extended image plane', in Proc. 17th IFAC World Congress, 6-11 July 2008, Seoul, Korea.

27 N. García, J.M. Sabater, J.M. Azorín, R. Saltaren and C. Pérez, 'Visual control of robots with changes of visibility in image features', IEEE Latin America, 4 (1), March (2006), 27-33 (in Spanish).

28 L. Gracia and C. Pérez, 'A new control scheme for visual servoing', Int. J. Control, Automation and Systems, 7 (2009).

29 R. Morales, Control visual para aplicación en separacion selectiva de lodos. 2008. Departamento de Ingeniería de Sistemas Industriales. Universidad Miguel Hernández.

30 P. J. Sequeira Gonçalves, L. F. Mendonça, J. M. Sousa and J. R. Caldas Pinto, 'Uncalibrated eyeto-hand visual servoing using inverse fuzzy models', IEEE Trans. Fuzzy Systems, 16 (2), (2008), $341-353$.

International Journal of Electrical Engineering Education 48/2 
31 P. J. Sequeira Gonçalves, A. Paris, C. Christo, J. M. C. Sousa and J. R. Caldas Pinto, 'Uncalibrated visual servoing in 3D workspace', in A. Campilho and M. Kamel (Eds.): Image Analysis and Recognition (Springer, Berlin, Heidelberg, 2006), pp. 225-236.

32 P. J. Sequeira Gonçalves J. M. C. Sousa and J. R. Caldas Pinto, 'Evolving fuzzy modeling of an uncalibrated visual servoing system', Lecture Notes in Computer Science (Springer, Berlin, Heidelberg, 2008), pp. 1041-1050.

33 J. M. Sebastián, L. Pari, L. Angel and A. Traslosheros, 'Uncalibrated visual servoing using the fundamental matrix', Robotics and Autonomous Systems, 57(1) (2009),

34 L. Pari, J. M. Sebastián, A. Traslosheros and L. Angel, 'Image based visual servoing: estimated image Jacobian by using fundamental matrix vs analytic Jacobian', in $\mathbf{\square}$ Image Analysis and Recognition (Springer, Berlin, Heidelberg, 2008).

35 L. Pari, Control Visual basado en Características de un Sistema Articular. Estimación del jacobiano de la Imagen Utilizando Múltiples Vistas, PhD Thesis, Universidad Politécnica de Madrid, 2007.

36 L. Pari, J. M. Sebastián, C. González and L. Ángel, 'Image based visual servoing: a new method for the estimation of the image jacobian in dynamic environments', in Lecture Notes in Computer Science (Springer, Berlin, 2006), pp. 850-861.

37 J. M. Sebastián, L. Pari, C. González and L. Ángel, 'A new method for the estimation of the image Jacobian for the control of an uncalibrated joint system' Lecture Notes in Computer Science (Springer, Berlin, 2005), pp. 631-638.

39 A. Hafez, Performance enhancement of visual servoing techniques, PhD Thesis, International Institute of Information Technology. India.

40 A. Hafez, Piyush Janawadkar and C. V. Jawahar, 'Robust visual servoing based on novel view prediction', CIRAS 2005, Singapore, Singapore.

41 A. Hafez and C. V. Jawahar, 'Target model estimation using particle filters for visual servoing', ICPR'06. Hong Kong. August 2006.

42 A. Hafez, Piyush Janawadkar and C. V. Jawahar, 'Novel view prediction for improved visual servoing', NCC 2006, New Delhi, India.

43 A. Hafez and C. V. Jawahar, 'Integration probabilistic framework for improved visual servoing in image and Cartesian spaces', IROS 2006, Bejing, China.

44 A. Hafez, and C. V. Jawahar, 'Probabilistic integration of 2D and 3D cues for visual servoing', ICARCV 2006, Singapore, Singapore.

45 A. Hafez and C. V. Jawahar, 'Minimizing a class of hybrid error functions for optimal pose alignment', ICARCV 2006, Singapure, Singapure.

46 A. Hafez, Uday Visesh Kumar and C. V. Jawahar, 'Combine texture and edges based on goodness weights for planar object tracking', ICRA 2007, Roma, Italy.

47 A. Hafez and C. V. Jawahar, 'A stable hybrid visual servoing algorithm', ICRA 2007, Roma, Italy.

48 O. Hornung and B. Heimann, 'A sequential control approach for visual servoing using uncalibrated system components', in Proc. 2nd Int. Conference on Machine Intelligence, ACIDCA-ICMI'2005, Tozeur, Tunisia, 2005, CD-ROM Proceedings.

49 O. Hornung and O. Heimann, 'Visual servoing by image trajectory generation and sequential control', in Proc. 9th IEEE Int. Conference on Methods and Models in Automation and Robotics, MMAR 2003, Miedzyzdroje, Poland, 2003 (IEEE, Piscataway, NJ, 2003), pp. 1059-1064.

50 O. Hornung and B. Heimann, 'A model-based approach for visual guided grasping with uncalibrated system components', Conference on Intelligent Robots and Systems (IROS 2005).

51 U. Reiser and J. Kubacki, 'Using a 3D time-of-flight range camera for visual tracking' FAC Symposium on Intelligent Autonomous Systems (IAV 2007), Toulouse, France.

52 J. Sales, R. Beltran, P. J. Sanz, R. Marín, R. Wirz, G. Leon, J. M. Claver and J. Alemany, 'The UJI industrial robotics telelaboratory: Real-time vision and networking,' in Proc. IROS 2008, pp. 4136.

53 A. Ryberg, A.-K. Christiansson and K. Eriksson, 'Accuracy Investigation of a vision based system for pose measurements', ICARCV 2006, pp. 1-6.

54 R. M. Prades, R. W. Gonzalez, P. J. Sanz Valero and A. Tirado, Recent Research Developments in Learning Technologies (Indugrafic, Badajoz, 2005). 
55 B. Fevery, B. Wyns, L. Boullart, J. R. Llata García and C. Torre Ferrero, 'Active security system for an industrial robot based on artificial vision and fuzzy logic principles', International Conference on Informatics in Control, Automation and Robotics 2008, Funchal, Madeira, Portugal.

56 A. Ryberg and A.-K. Christiansson et al., 'Accuracy investigation of a vision based system for pose measurements, IEEE Int. Conf on Control, Automation, Robotics and Vision, Singapore, pp. 1163 1168.

57 A. Ryberg and A.-K. Christiansson et al., 'A new camera model and algorithms for higher accuracy and better convergence in vision-based pose calculations', ICMA 2006, Luo Yang, China, 2006, pp. 194-199.

58 A. Ryberg and A.-K. Christiansson et al., 'A new camera model and algorithms for higher accuracy pose calculations' in IEEE Int. Symp. on Industrial Electronics, Montreal, Canada, 2006 (IEEE, Piscataway, NJ, 2006), pp. 2798-2802.

$2059 \mathrm{H}$-index in Wikipedia. http://en.wikipedia.org/wiki/H-index

International Journal of Electrical Engineering Education 48/2 


\section{AUTHOR QUERY FORM}

Journal: International Journal of Electrical Engineering Education Article:

Dear Author:

During the preparation of your manuscript for publication, the questions listed below have arisen. Please attend to these matters and return this form with your proof.

Many thanks for your assistance.

\begin{tabular}{|l|l|l|}
\hline $\begin{array}{l}\text { Query } \\
\text { References }\end{array}$ & Query & Remarks \\
\hline 1. & author? But 20 students? & \\
\hline 2. & Au: please match student names in Figs & \\
\hline 3. & Au: of what? & \\
\hline 4. & Au: is this time spent on the course? & \\
\hline 5. & Au: Please acknowledge students here & \\
\hline 6. & $\begin{array}{l}\text { Authors: please give all details of conf proceedings: location, } \\
\text { full date, publisher, date publishes, pages }\end{array}$ & \\
\hline 7. & Au: WHERE? Full date? & \\
\hline 8. & AU: pages? & \\
\hline 9. & Au: please translate & \\
\hline 10. & Au: in eds?? Give title - this is the series title? & \\
\hline 11. & Au: pages? & \\
\hline 12. & Au: Eds? & \\
\hline 13. & Au: please translate title & \\
\hline 14. & Au: details? Book or journal? & \\
\hline 15. & Au: details? Book or journal? & \\
\hline 16. & Au: details? & Au: details? \\
\hline 17. & Au: details? & \\
\hline 18. & AUTHOR? Please check all details, is this correct? & \\
\hline 19. & au: this is not acceptable as a journal reference. Please find an & \\
\hline 20. & & \\
\hline
\end{tabular}

